\title{
Predictors of Sexual Orientation Diversity in Intercollegiate Athletics Departments
}

\author{
George B. Cunningham \\ Texas A\&M University
}

\begin{abstract}
In adopting a multilevel perspective, the purpose of this study was to examine antecedents of sexual orientation diversity among university athletic departments. Data were gathered from top administrators $(N=653)$ in 199 athletic departments. Hierarchical regression analysis indicated that the size of the university, the racial diversity of department employees, and the gender diversity of department employees were all positively associated with sexual orientation diversity. The entire model explained $24 \%$ of the variance. The author discusses ways to increase sexual orientation diversity, study contributions, limitations, and future directions.
\end{abstract}

Lesbian, gay, bisexual, and transgendered (LGBT) individuals face considerable prejudice and discrimination in the workplace. In the United States, sexual orientation is not protected under federal employment laws, making it legal to base employment decisions on one's sexual orientation. Not surprisingly, LGBT persons face sexual prejudice, or bias expressed toward LGBT individuals (Herek, 2000), on a regular basis. For instance, in Hebl, Foster, Mannix, and Dovidio's (2002) clever experiment, confederates applied for jobs at a local mall, and wore a hat that read either "Texan and Proud" or "Gay and Proud" (the applicant did not know which hat when she or he applied for the job). Though the confederates did not face overt discrimination, they did face more subtle forms of bias: employers spoke fewer words to, spent less time with, and interacted more negatively with the presumed LGBT applicant than they did with the presumed heterosexual applicant. LGBT employees also face on-the-job discrimination. One in eight LGBT persons in Ragins, Singh, and Cornwell's (2007) study reported being reassigned from a job based on their sexual orientation, and 6\% reported being fired for the same reason. Others studies have demonstrated that sexual minorities face wage discrimination (Blanford, 2003), are negatively affected by employer benefit packages favoring heterosexual relationships (Human Rights Campaign, 2009), and face discrimination that negatively impacts their work experiences (Button, 2001; Ragins, 2004; Ragins \& Cornwell, 2001) career progression (Ragins, 2004; Ragins \& Cornwell, 2001), and physical well-being (Smith \& Ingram, 2004).

Researchers have observed a similar pattern of findings in sport organizations. Sexual prejudice is high among current and future sport and exercise profession-

Cunningham is with the Laboratory for Diversity in Sport, Dept. of Health and Kinesiology, Texas A\&M University, College Station, TX. 
als (Gill, Morrow, Collins, Lucey, \& Schultz, (2006), current and former athletes (Sartore \& Cunningham, 2009, Study 1), and parents of athletes (Sartore \& Cunningham, 2009, Study 2). This prejudice is a primary determinant in various forms of discrimination and exclusion, including the preference for heterosexual coaches (Sartore \& Cunningham, 2009) and the ostracism and physical violence directed toward LGBT athletes (Anderson, 2002; Plummer, 2006). Employees also face antagonistic work environments. As one example, a coach in Krane and Barber's (2005) qualitative study discussed how "the coaching world is not always a kind world....It's a really strange issue within coaching....There are so many lesbians in coaching, and yet it's not somewhere that people can be comfortable with that being openly known about them" (p. 71). Others have found that LGBT job seekers face access discrimination and subtle forms of prejudice in the selection process (Cunningham, Sartore, \& McCullough, 2010).

While the aforementioned research paints a rather dismal picture for LGBT employees, there are exceptions. For example, the Human Rights Campaign (HRC) publishes the Corporate Equality Index (see www.hrc.org/cei) every two years. This index assesses the degree to which Fortune 1000 firms (a) have nondiscriminatory policies pertaining to sexual orientation and gender identity, (b) have partner benefits, (c) maintain LGBT resource groups, (d) engage in appropriate advertising, marketing, and sponsorship of LGBT events and organizations, and (e) exhibit responsible behaviors toward the LGBT community. Examination of the data shows that while some high-performing firms excel (e.g., Hewlett Packard), other firms (e.g., Exxon) do not fare well on the Index. Unfortunately, given that the focus of the Corporate Equality Index is on Fortune 1000 firms, sport organizations are not included in the analysis.

Thus, while LGBT individuals face considerable discrimination and ostracism in various employment contexts, there are some workplaces where sexual orientation diversity is high. Disappointingly, however, examination of such issues in the sport context is lacking. As such, the purpose of this study was to examine the sexual orientation diversity of university athletic departments and factors contributing to that end. In drawing from a multilevel approach, I hypothesized that both macrolevel (i.e., size of the university, legality of same-sex marriage) and meso-level factors (i.e., employee diversity and diversity strategy) would be associated with the sexual orientation diversity among National Collegiate Athletic Association (NCAA) Division III athletic departments. In the following section, I present the conceptual framework guiding the study and offer the specific hypotheses.

\section{Conceptual Framework}

Following past diversity research (Benschop, 2006; Cunningham \& Sagas, 2008; Prasad, Pringle, \& Konrad, 2006), I adopt a multilevel perspective in developing the conceptual framework for this study. Multilevel analysis offers advantages over models at a single level of analysis, including the ability to address the complexity of relationships among variables. After all, "organizations are multi-level systems" (Kozlowski \& Klein, 2000, p. 3), and as such, activities that take place at one level of analysis can influence outcomes at other (or the same) levels. Failure to take into account these complexities can potentially result in an incomplete understanding of a given phenomenon. Consequently, in formulating the conceptual framework 
for this study, I focused on how factors at the macro- and meso-levels of analysis might be associated with sexual orientation diversity of university athletic departments.

\section{Macro-Level Factors}

I included two macro-level factors in the analysis: size of the university and legality of same-sex marriage. The size of the university is likely to be positively associated with the athletic department's sexual orientation diversity for several reasons. First, large universities are generally located in major cities and metropolitan areas. Consider, for instance, that the ten largest American public universities in 2009-2010 were located in cities with an average population of 290,066 - a figure considerably larger than the population of the average city in the U.S. $(8,955$ residents; www.nlc.org). This is noteworthy because larger communities are also likely to have greater diversity (Hall \& Lee, 2010), and as diversity within a given social context increases, so too does attention to social justice and equality (for similar arguments, see Eagly \& Chin, 2010; Fassinger, Shullman, \& Stevenson, 2010). These dynamics help explain why most of the top gay-friendly cities to live are major cities or metropolitan areas (see www.advocate.com). Thus, within the context of the current study, it is possible that LGBT employees would be more attracted to larger universities because they are situated within large cities where equality and social justice are valued.

From a different perspective, larger organizations have more monies and resources to devote to LGBT equality. Data drawn from a recent Human Rights Campaign report (2009) illustrates these dynamics: Fortune 100 companies are more likely to have nondiscriminatory policies directed toward sexual orientation (94\%), to have nondiscriminatory policies directed toward gender identity (60\%), and to provide partner benefits $(83 \%)$ than are Fortune $500(88 \%, 35 \%$, and $57 \%$, respectively) or Fortune 1000 (69\%, 21\%, and 39\%, respectively) companies. It is possible that similar dynamics occur among educational institutions, such that larger universities are more likely to have LGBT-friendly policies than are their counterparts. Such policies are critical to affirming sexual orientation diversity (Button, 2001) and therefore likely to attract LGBT employees to the university, including athletic department staff.

Collectively, this literature suggests that, due to a host of factors, the size of the university might have a positive link with the LGBT athletic department employees. Thus, I hypothesized that the size of the university would be positively associated with sexual orientation diversity (hypothesis 1 ).

Another macro-level factor examined in this study was whether the university was located in a state that supported same-sex marriage. As of 2010, same-sex marriage was only legal in five states (Massachusetts, Connecticut, Iowa, New Hampshire, and Vermont) and the District of Columbia. It is possible that a state's stance on marriage equality would serve to either attract or deter LGBT persons to that area. After all, people might be reticent to live in areas where they are denied the rights that others enjoy. Thus, athletic departments located in states where samesex marriage is legal might have more LGBT employees than do their counterparts. This relationship suggests that the legality of same-sex marriage will be positively associated with sexual orientation diversity (hypothesis 2). 


\section{Meso-Level Factors}

In addition to examining the effects of the macro-level factors, I also included two meso-level (i.e., organizational-level) antecedents of sexual orientation diversity: employee demographic diversity and the department's diversity strategy. With respect to the first factor, employee diversity, there is some evidence that "diversity begets diversity," such that organizations diverse in some areas are also likely to be diverse in others. For instance, in a study of track and field coaching staffs, Cunningham (2007) observed that age and racial diversity were positively associated with deep-level diversity on the staff.

Several possible explanations for these relationships exist. First, it is possible that sport managers making personnel decisions consciously seek to maintain a diverse workplace along multiple diversity dimensions, including both surface-level and deep-level characteristics. This desire likely emanates from belief that differences among employees bring considerable benefits to the organization (Doherty \& Chelladurai, 1999; see also Cunningham \& Singer, 2009). Alternatively, LGBT employees might be attracted to workplaces where visible diversity is salient. As Pugh, Dietz, Brief, and Wiley (2008) note, surface-level diversity can serve as an "extracted cue in which people develop a larger sense of what is occurring" (p. 1424, emphasis original). That is, people form estimates about the diversity and inclusion of a workplace based on the visible cues of that organization, such as the demographic diversity of the workforce. In the current context, this would suggest that LGBT employees would be attracted to an already demographically diverse athletic department because they believe that such diversity signals positive diversity-related elements of the department.

Both possibilities suggest that sexual orientation diversity should be high in athletic departments where surface-level diversity (i.e., age, racial, and gender diversity) are also high. Thus, I hypothesized that age diversity (hypothesis 3a), racial diversity (hypothesis 3b), and gender diversity (hypothesis 3c) will all be positively associated with sexual orientation diversity.

Finally, I expected that the department's diversity strategy, or "the purposeful use of processes and strategies that make... differences among people into an asset rather than a liability for the organization" (Hayes-Thomas, 2004, p. 12), would impact the sexual orientation diversity of the department. While many researchers have offered frameworks, only Fink and Pastore's (1999) has received empirical support (Cunningham, 2009; Fink, Pastore, \& Riemer, 2001, 2003); thus, it serves as the foundation for this analysis. These authors outlined four approaches organizations use in managing diversity: noncompliance, compliance, reactive, and proactive. Of the four, the authors argued that a proactive diversity strategy was the most effective, and empirical analysis supports this contention (Cunningham, 2009; Fink et al., 2001, 2003); thus, it serves as the focus of the current investigation.

Athletic departments adhering to a proactive diversity management strategy are likely to (a) adopt an encompassing, gestalt view of diversity (Golembiewski, 1995; Holladay, Knight, Paige, \& Quinones, 2003); (b) value diversity, and systemically integrate diversity initiatives throughout all organizational activities and functions (Allen \& Montgomery, 2001; Cunningham \& Singer, 2009); (c) promote open lines of communication, with diverse personnel holding key power and decision making positions (Doherty \& Chelladurai, 1999; Ely \& Thomas, 2001); and (d) 
actively anticipate diversity-related problems while taking steps to assuage such concerns (Doherty \& Chelladurai, 1999; Fink \& Pastore, 1999). Fink and Pastore suggested that organizations adopting such a perspective toward diversity would outperform their counterparts because of the many benefits diversity bring to the workplace. Empirical evidence supports this contention, as, relative to their counterparts, athletic departments that adopt a proactive strategy report better group functioning (Fink et al., 2001, 2003), more positive employees attitudes (Fink et al., 2001, 2003), and superior performance (Cunningham, 2009).

In the current study, I expected that departments following a proactive strategy would also have greater sexual orientation diversity. Consider, for instance, that proactive departments adopt an encompassing view of diversity, and as such, sexual orientation diversity is likely to be included. Furthermore, LGBT employees are likely to be attracted to athletic departments following a proactive strategy because they would be unlikely to experience prejudice and discrimination in those workplaces. This rationale is consistent with Schneider's (1987) attraction-selectionattrition (ASA) theory, which suggests that people are attracted to organizations, and likewise organizations to people, based on the presumed value congruence between the two. Therefore, I hypothesized that a proactive diversity strategy would be positively associated with sexual orientation diversity (hypothesis 4).

\section{Method}

\section{Participants}

NCAA Division III athletic administrators $(N=653)$ participated in the study. The sample was comprised of 385 men $(59.0 \%), 263$ women $(40.3 \%)$ and 5 persons who did not indicate their sex $(.8 \%)$. Participant ages were widely distributed: $18-30$ years $(n=110,16.8 \%), 31-40$ years $(n=176,27.0 \%), 41-50$ years $(n=$ $178,27.3 \%), 51-60$ years $(n=148,22.7 \%), 61$ years or older $(n=36,5.5 \%)$, and persons who did not provide their age $(n=5, .8 \%)$. Most of the sample was White $(n=599,91.7 \%)$, followed by African American $(n=27,4.1 \%)$, Hispanic $(n=6$, $.9 \%)$, Asian $(n=5, .8 \%)$, Native American $(n=5, .8 \%)$, persons who listed "other" $(n=2, .3 \%)$, and persons who did not provide their race $(n=9,1.4 \%)$. Finally, the mean organizational tenure was 11.52 years $(S D=9.92)$, while the mean occupational tenure was 18.30 years $(S D=10.92$ years $)$.

\section{Measures}

Participants completed a questionnaire in which they provided their demographic information and responded to items assessing the employee diversity of the department and the diversity strategy the department used. Information pertaining to samesex marriage and the size of the university were collected from secondary sources.

Employee Diversity. The age diversity, racial diversity, gender diversity, and sexual orientation diversity of the departmental workforce were all assessed using single-item measures adapted from Harrison and colleagues' work (Harrison, Price, \& Bell, 1998; Harrison, Price, Gavin, \& Florey, 2002). The stem read: "As a whole, how different are members of your athletic department with respect to:", 
and the individual items included "age," "race," "sex," and "sexual orientation." Participants responded on a 7-point scale from 1 (very similar) to 7 (very different). Harrison et al. (1998, 2002) demonstrated the sound psychometrics of these measures, and other researchers have used them extensively in diversity research (e.g., Cunningham, 2006, 2007).

Diversity Strategy. Fink and colleagues have traditionally used multi-item instruments to assess the department's diversity strategy (25 items in Fink et al., 2001; 26 items in Fink et al., 2003). More recently, Cunningham (2009) used a vignette, an approach consistent with business strategy literature (e.g., Cunningham, 2002; Snow \& Hrebiniak, 1980). Researchers have shown this method to be as reliable and valid as using multi-item instruments (Snow \& Hrebiniak, 1980) while also having the advantage of significantly cutting down on the time commitment and mental fatigue entailed in completing long questionnaires.

Following Cunningham (2009), the vignette asked administrators to indicate "how similar your department is to the one in the scenario." The vignette read: "This department has flexible work hours and schedules, and attempts to make everyone feel as if they contribute to the department. Building and managing diversity is included in the department's mission, and there are open lines of communication aimed at gleaning the advantages of diversity. Strategies, policies, and procedures are in place in order to capitalize on individual differences. The department also manages diversity by anticipating problems and initiating incentives to prevent problems." Participants then rated how similar their department was to the one described in the vignette on a scale from 1 (very different) to 7 (very similar). Cunningham provided validity evidence of the measure.

Same-Sex Marriage. Same-sex marriage is legal in five states-Massachusetts, Connecticut, Iowa, New Hampshire, and Vermont - and the District of Columbia. Universities located in these states were coded as places where same-sex marriage is legal, while all other states were coded as places where such unions are illegal.

University Size. Data concerning university size was obtained from the Equity in Athletics Report, available at http://www.ope.ed.gov/athletics/.

\section{Procedures}

As part of a larger study, data were collected from top athletic administrators ( $n=1376)$ of all NCAA Division III athletic departments $(n=444)$. Recognizing the need for repeated contact to increase responses rates (Dillman, 2000), administrators were first mailed postcards alerting them to the study. One week later, questionnaire packets, which included a cover letter explaining the purpose of the study, questionnaire, and postage-paid return envelope, were mailed to all administrators, and this was followed by a reminder postcard one week later. Two weeks after the first questionnaire packet was mailed, a second questionnaire packet was mailed, with the cover letter thanking those who had completed the questionnaire already for their participation and encouraging nonrespondents to participate. A total of 455 persons responded to the first round of questionnaires, and an additional 198 responded to the second round, bringing the total sample to 653 (47.94\% response rate). 
Several steps were taken to examine the representativeness of the sample. First, I compared the mean scores of early and late responders, as late responders are considered to have similar characteristics as nonrespondents (Rogelberg $\&$ Luong, 1998). A multivariate analysis of variance indicated that early and late respondents did not differ in their ratings of any variables, $F(5,572)=1.88, p>$ .05. Thus, while late respondents "are not 'pure' nonrespondents" (Rogelberg \& Luong, 1998, p. 63), nonresponse bias may not be a substantial concern (see also Rogelberg \& Stanton, 2007).

As another check, I compared the sample's demographics to those in the population. Analysis indicated that the sample was slightly more racially diverse (91.7\% White) compared with the population of Division III athletic directors, associate athletic directors, assistant athletic directors, and senior women administrators $(94.4 \%$; Zgonc, 2010). On the other hand, there were fewer women in the sample $(40.3 \%)$ than in the comparable population (52.5\%; Zgonc, 2010). As a collective, however, the two sets of analyses suggest that the sample is representative.

\section{Results}

\section{Data Aggregation}

While the data were collected from individual athletic administrators, the hypotheses were developed at the group level of analysis. Thus, it was first necessary to aggregate the data from the individual to the group level. I computed interrater agreement $\left(r_{w g}\right)$ values and eta square $\left(\eta^{2}\right)$ values to determine the statistical appropriateness of doing so. Interrater agreement values appraise the extent to which members of a particular group consistently rate a construct, while eta square values assess the extent to which there is sufficient variance between groups (for additional information, see Bleise, 2000; Dixon \& Cunningham, 2006). As seen in Table 1 , all $\mathrm{r}_{\mathrm{wg}}$ values were above the traditional .70 cutoff (James, Demaree, \& Wolf, 1993), while all eta square values were above the traditional cutoff of .20 (Florin, Giamartino, Kenny, \& Wandersman, 1990). These results provide statistical support for aggregating the data from the individual to the group level. As such, the athletic department served as the unit of analysis, and the sample size decreased to 199 departments.

\section{Table 1 Data Aggregation Statistics}

\begin{tabular}{lccc}
\hline Variable & $\boldsymbol{F}$ & $\boldsymbol{\eta}^{2}$ & $\mathbf{r}_{\mathbf{w g}}$ \\
\hline Age diversity & $1.61 * * *$ & .53 & .79 \\
Racial diversity & $1.72 * * *$ & .54 & .87 \\
Gender diversity & $1.24 *$ & .46 & .80 \\
Sexual orientation diversity & $2.63 * * *$ & .67 & .75 \\
Proactive diversity strategy & $1.30 *$ & .47 & .80 \\
\hline
\end{tabular}

Notes. $* p<.05 . * * * p<.001$. 


\section{Descriptive Statistics}

Means, standard deviations, and bivariate correlations are presented in Table 2. The mean score for sexual orientation diversity was low $(M=2.88, S D=1.43)$ and significantly lower than the midpoint of the scale (4), $t(197)=-10.97, p<.001$. The mean score was significantly lower than that of gender diversity, $t(197)=$ -7.98, $p<.001$, and age diversity, $t(197)=-12.91, p<.001$, though it was higher than the mean score for racial diversity, $t(197)=8.06, p<.001$. Further examination of the data show that the mean scores ranged from 1 to 7 . Interestingly, the mean scores for 35 of the athletic departments was 1, indicating a complete lack of sexual orientation diversity. I further examined the number of departments with mean scores less than 3, which would indicate low sexual orientation diversity, and those with mean scores greater than 5 , which would indicate high sexual orientation diversity. These analyses suggest that departments were more likely to have low sexual orientation diversity $(n=96,48.24 \%$ of the sample) than they were to have high sexual orientation diversity $(n=19,9.54 \%)$

Table 2 Means, Standard Deviations, and Bivariate Correlations

\begin{tabular}{|c|c|c|c|c|c|c|c|c|c|}
\hline Item & $M$ & $S D$ & 1 & 2 & 3 & 4 & 5 & 6 & 7 \\
\hline $\begin{array}{l}\text { 1. Same-sex } \\
\text { marriage }\end{array}$ & .16 & .37 & - & & & & & & \\
\hline $\begin{array}{l}\text { 2. University } \\
\text { size }\end{array}$ & 2547.57 & 2159.83 & .00 & - & & & & & \\
\hline 3. Age diversity & 4.32 & .93 & -.10 & .14 & - & & & & \\
\hline $\begin{array}{l}\text { 4. Racial diver- } \\
\text { sity }\end{array}$ & 2.01 & 1.06 & .04 & $.16^{*}$ & .13 & - & & & \\
\hline $\begin{array}{l}\text { 5. Gender } \\
\text { diversity }\end{array}$ & 3.67 & .88 & .05 & .05 & $.15^{*}$ & $.27 * * *$ & - & & \\
\hline $\begin{array}{l}\text { 6. Proactive } \\
\text { diversity } \\
\text { strategy }\end{array}$ & 4.61 & 1.00 & $-.18 * *$ & .09 & -.05 & .09 & .04 & - & \\
\hline $\begin{array}{l}\text { 7. Sexual ori- } \\
\text { entation diver- } \\
\text { sity }\end{array}$ & 2.88 & 1.43 & .04 & $.24 * *$ & $.18 *$ & $.29 * * *$ & $.36 * * *$ & .04 & - \\
\hline
\end{tabular}

Notes. $* p<.05, * * p<.01, * * * p<.001$.

In terms of the bivariate correlations, sexual orientation diversity was significantly associated with the size of the university and all three diversity dimensions, though it was not correlated with same-same marriage legality or the diversity culture of the workplace.

\section{Hypothesis Testing}

The hypotheses were tested by way of a hierarchical regression analysis with sexual orientation diversity serving as the dependent variable. Consistent with the 
multilevel conceptual model developed for this study, I entered the macro-level factors (i.e., legality of same-sex marriage and university size) in Step 1, and then entered the meso-level factors (i.e., age diversity, racial diversity, gender diversity, and proactive diversity strategy) in Step 2 . The variance inflation factors were all less than 1.2 and the condition index was 21.31. These values are below the cutoff points recommended by Hair, Black, Babin, Anderson, and Tatham (2006), thereby suggesting that multicollinearity was not a concern.

Results of the regression analysis are presented in Table 3. The first step accounted for $6 \%(p<.01)$ of the variance in sexual orientation diversity. Consistent with hypothesis 1 , the size of the university was positively associated with sexual orientation diversity $(\beta=.24, p<.01)$. However, contrary to hypothesis 2 , the university being located in a state that allowed same-sex marriage did not affect the sexual orientation of the department $(\beta=.01, p=.92)$.

\section{Table 3 Effects of Macro-Level and Meso-Level Factors on Sexual Orientation Diversity}

\begin{tabular}{lccccc}
\hline Step & $\boldsymbol{B}$ & $\boldsymbol{S E}$ & $\boldsymbol{\beta}$ & $\boldsymbol{R}^{\mathbf{2}}$ & $\boldsymbol{\Delta}^{\mathbf{2}}$ \\
\hline Step 1 & & & & .06 & $.06^{* *}$ \\
Same-sex marriage legality & .03 & .30 & .01 & & \\
University size & .01 & .01 & $.24^{* *}$ & & \\
Step 2 & & & & .24 & $.18^{* * *}$ \\
Age diversity & .08 & .11 & .05 & & \\
Racial diversity & .25 & .10 & $.18^{* *}$ & & \\
Gender diversity & .54 & .12 & $.33^{* * *}$ & & \\
Proactive diversity strategy & -.06 & .10 & -.04 & & \\
\hline
\end{tabular}

Notes. $* p<.05, * * p<.01, * * * p<.001$.

After accounting for the macro-level factors, the meso-level factors contributed an additional $18 \%(p<.001)$ unique variance. Hypothesis 3 a was not supported, as age diversity was not significantly associated with sexual orientation diversity $(\beta=.05, p=.46)$. However, both racial diversity $(\beta=.18, p<.01)$ and gender diversity $(\beta=.33, p<.001)$ were positively associated with sexual orientation diversity; thus, hypotheses $3 \mathrm{~b}$ and $3 \mathrm{c}$ were supported, respectively. Finally, the diversity strategy was not associated with sexual orientation diversity $(\beta=-.04, p$ $=.57$ ), and therefore, hypothesis 4 was rejected.

\section{Discussion}

The purpose of this study was to examine antecedents of sexual orientation diversity among NCAA Division III athletic departments. This investigation was spurred, in part, by the continued evidence of prejudice and discrimination expressed toward 
sexual minorities in the sport context (Anderson, 2002; Cunningham et al., 2010; Gill et al., 2006; Krane \& Barber, 2005; Sartore \& Cunningham, 2009). In line with those studies, results indicate that sexual orientation diversity was low among the participating athletic departments and significantly lower than either gender or age diversity. Furthermore, roughly $46 \%$ of the athletic departments were classified as having low sexual orientation diversity, while over $17 \%$ of the athletic departments indicated that there was no sexual orientation diversity in the department. Collectively, these findings lend support to the notion that sport is place characterized by heterosexism and sexual prejudice, and where opportunities for LGBT individuals is limited.

Despite the lack of access for LGBT individuals to work in athletics, some of the athletic departments had high sexual orientation diversity, and the results indicated several key antecedents of such heterogeneity. With respect to the macrolevel influences, the size of the broader university was significantly associated with sexual orientation diversity. This is consistent with past research showing that larger organizations engage in more diversity-related activities than do their smaller counterparts (Human Rights Campaign, 2009). In keeping with the multilevel approach, this finding could also be a function of the larger cities in which large universities are usually situated. Such locales generally have greater diversity (Hall \& Lee, 2010), and their citizens are oftentimes more prone to express an interest in diversity and social justice (see also Eagly \& Chin, 2010; Fassinger et al., 2010). All of these factors potentially contribute to the greater sexual orientation diversity observed at large universities.

Two meso-level factors also contributed to the sexual orientation diversity of the department: racial diversity and gender diversity. These findings compliment past research showing a positive association among different diversity dimensions (Cunningham, 2007) and also suggest that demographic diversity in the department might serve as a positive cue for job seekers. In this way, people likely form estimates about an athletic department's diversity and inclusion based on visible cues they can gather (see also Pugh et al., 2008). These cues can include a host of factors, such as the trophies displayed, the pictures on the wall, or in the current context, the employees' racial and gender diversity. Consequently, surface-level diversity begets more deep-level differences among employees.

On the contrary, others factors thought to predict sexual orientation diversity did not. At the macro-level, this included the legality of same-sex marriage. This is possibly due to so few states allowing such unions and the limitations it would place on LGBT athletic personnel's employment options. As more states allow same-sex marriage, it is possible that LGBT employees can be more discerning in the departments in which they work, and as a result, greater LGBT diversity will be observed in states where same-sex marriage is legal.

Two meso-level factors also failed to predict sexual orientation diversity. The first, age diversity, could be due to the high levels of age diversity throughout most departments, as evidenced by the high mean score and tight standard deviation (Table 2). Thus, this diversity form might be standard throughout departments and, unlike gender and racial diversity, not serve as an "extracted cue" (Pugh et al., 2008, p. 1424) from which potential employees can gather a larger sense of the workplace. Another meso-level factor, the diversity strategy, also failed to predict sexual orientation diversity. Doherty and Chelladurai (1999) note that inclusive 
diversity management strategies might not be associated with positive outcomes if the accompanying employee diversity is lacking. Cunningham (2009) provided empirical evidence of as much, as athletic departments in his study that coupled a proactive diversity strategy with employee diversity outperformed their counterparts. These studies suggest that the diversity strategy might not provide main (direct) effects on the recruitment and retention of LGBT employees, but rather, the strategy might interact with other elements, such as other diversity forms or other policies in place, to predict sexual orientation diversity. Future research is needed to examine this possibility.

\section{Contributions, Limitations, and Future Directions}

This study offers many contributions to the diversity literature. First, while other researchers have focused on the experiences of and opportunities for LGBT persons in sport (e.g., Anderson, 2002; Cunningham et al., 2010; Gill et al., 2006; Krane \& Barber, 2005; Sartore \& Cunningham, 2009), this is the first study identified that examined sexual orientation diversity of a sport organization's workforce. Second, the multilevel approach adopted in this study serves as a contribution to the literature. As Dixon and Cunningham (2006) noted, it is through the "formulation of multilevel perspectives and theories that we are able to gain a richer understanding of behavior" (p. 88). Consistent with this position, I found that both macro- and meso-level factors contributed to athletic departments' sexual orientation diversity. Focusing only on one level of analysis would have yielded partial and incomplete results.

Despite the strengths of the study, there are potential limitations. First, I focused on a single NCAA division and recognize that researchers might observe a different pattern of findings in different contexts. Thus, caution should be used when generalizing the results to other sport settings. Second, some might view the response rate as low: $47.94 \%$ of the administrators surveyed responded to the questionnaire, and after the data aggregation, the analysis included $44.82 \%$ of all NCAA Division III athletic departments. It is important to note, however, that given the sensitive nature of this study, some (e.g., Berdahl \& Aquino, 2009) have argued that response rates similar to this study are "good" (p. 37 and p. 41). Further, additional statistical tests showed that early and late responders did not differ, thereby reducing concerns of nonresponse bias (Rogelberg \& Stanton, 2007).

Finally, there are several possibilities for future research. First, subsequent analyses are needed in different sport contexts (e.g., NCAA Division I departments, fitness organizations, nonprofit sport clubs) to better understand the predictors of sexual orientation diversity. In a related way, this is a U.S.-focused study, both in terms of the data collection and the literature reviewed. Clearly, sexual orientation diversity is an issue with world-wide relevance. Future research is needed to reflect as much. Third, what impact does sexual orientation diversity have on workplace outcomes? Research suggests that different perspectives and backgrounds should result in better decision making, more creative decisions, and the attraction of diverse customers (see van Knippenberg \& Scippers, 2007). Additional inquiry is needed to examine whether sexual orientation diversity is associated with these important work outcomes. Indeed, given the prevalence of sexual prejudice and discrimination in sport, all efforts to understand how sport organizations create diverse and inclusive workplaces are not only needed, but welcome. 


\section{Acknowledgment}

This research was funded by a grant from the National Collegiate Athletic Association (NCAA).

\section{References}

Allen, R.S., \& Montgomery, K.A. (2001). Applying an organizational development approach to creating diversity. Organizational Dynamics, 30, 149-161.

Anderson, E. (2002). Openly gay athletes: Contesting hegemonic masculinity in a homophobic environment. Gender \& Society, 16, 860-877.

Benschop, Y. (2006). Of small steps and the longing for giant leaps: Research on the intersection of sex and gender within workplaces and organizations. In A.M. Knorad, P. Prasad, \& J.K. Pringle (Eds.), Handbook of workplace diversity (pp. 273-298). Thousand Oaks, CA: Sage.

Berdahl, J.L., \& Aquino, K. (2009). Sexual behavior at work: Fun or folly? Journal of Applied Psychology, 94, 34-47.

Blanford, J.M. (2003). The nexus of sexual orientation and gender in the determination of earnings. Industrial \& Labor Relations Review, 56, 622-642.

Bleise, P. D. (2000). Within-group agreement, non-independence, and reliability: Implications for data aggregation and analysis. In K. J. Klein and S. W. J. Kozlowski (Eds.), Multilevel theory, research, and methods in organizations: Foundations, extensions, and new directions (pp. 349-381). San Francisco, CA: Jossey-Bass.

Button, S.B. (2001). Organizational efforts to affirm sexual diversity: A cross-level examination. Journal of Applied Psychology, 86, 17-28.

Cunningham, G.B. (2002). Examining the relationship among Miles and Snow's strategic types and measures of organizational effectiveness in NCAA Division I athletic departments. International Review for the Sociology of Sport, 37, 159-175.

Cunningham, G.B. (2006). The influence of demographic dissimilarity on affective reactions to physical activity classes. Journal of Sport \& Exercise Psychology, 28, 127-142.

Cunningham, G.B. (2007). Perceptions as reality: The influence of actual and perceived demographic dissimilarity. Journal of Business and Psychology, 22, 79-89.

Cunningham, G.B. (2009). The moderating effect of diversity strategy on the relationship between racial diversity and organizational performance. Journal of Applied Social Psychology, 36, 1445-1460.

Cunningham, G.B., \& Sagas, M. (2008). Gender and sex diversity in sport organizations: Introduction to a special issue. Sex Roles, 58, 3-9.

Cunningham, G.B., \& Singer, J.N. (2009). Diversity in athletics: An assessment of exemplars and institutional best practices. Indianapolis, IN: National Collegiate Athletic Association.

Cunningham, G.B., Sartore, M.L., \& McCullough, B.P. (2010). The influence of applicant sexual orientation and rater sex on ascribed attributions and hiring recommendations of personal trainers. Journal of Sport Management, 24, 400-415.

Dillman, D. A. (2000). Mail and Internet surveys: The tailored design method (2 $\left.2^{\text {nd }} \mathrm{ed}.\right)$. New York: John Wiley \& Sons.

Dixon, M.A., \& Cunningham, G.B. (2006). Multi-level analysis in sport management: Conceptual issues and review of aggregation techniques. Measurement in Physical Education and Exercise Science, 10(2), 85-107.

Doherty, A.J., \& Chelladurai, P. (1999). Managing cultural diversity in sport organizations: A theoretical perspective. Journal of Sport Management, 13, 280-297.

Eagly, A.H., \& Chin, J.L. (2010). Diversity and leadership in a changing world. American Psychologist, 65, 216-224. 
Ely, R.J., \& Thomas, D.A. (2001). Cultural diversity at work: The effects of diversity perspectives on work group processes and outcomes. Administrative Science Quarterly, 46, 229-273.

Fassinger, R.E., Shullman, S.L., \& Stevenson, M.R. (2010). Toward an affirmative lesbian, gay, bisexual, and transgendered leadership paradigm. American Psychologist, 65, 201-215.

Fink, J.S., \& Pastore, D.L. (1999). Diversity in sport? Utilizing the business literature to devise a comprehensive framework of diversity initiatives. Quest, 51, 310-327.

Fink, J.S., Pastore, D.L., \& Riemer, H.A. (2001). Do differences make a difference? Managing diversity in Division IA intercollegiate athletics. Journal of Sport Management, $15,10-50$.

Fink, J.S., Pastore, D.L., \& Riemer, H.A. (2003). Managing employee diversity: Perceived practices and organizational outcomes in NCAA Division III athletic departments. Sport Management Review, 6, 147-168.

Florin, P., Giamartino, G.A., Kenny, D.A., \& Wandersman, A. (1990). Levels of analysis and effects: Clarifying group influence and climate by separating individual and group effects. Journal of Applied Social Psychology, 20, 881-900.

Gill, D.L., Morrow, R.G., Collins, K.E., Lucey, A.B., \& Schultz, A.M. (2006). Attitudes and sexual prejudice in sport and physical activity. Journal of Sport Management, 20, 554-564.

Golembiewski, R. (1995). Managing diversity in organizations. Tuscaloosa, AL: The University of Alabama Press.

Hair, J.F., Jr., Black, W.C., Babin, B.J., Anderson, R.E., \& Tatham, R.L. (2006). Multivariate data analysis (6th ed.). Upper Saddle River, NJ: Pearson.

Hall, M., \& Lee, B. (2010). How diverse are US suburbs? Urban Studies 47, 3-28.

Harrison, D.A., Price, K.H., \& Bell, M.P. (1998). Beyond relational demography: Time and the effects of surface- and deep-level diversity on work group cohesion. Academy of Management Journal, 41, 96-107.

Harrison, D.A., Price, K.H., Gavin, J.H., \& Florey, A.T. (2002). Time, teams, and task performance: Changing effects of surface- and deep-level diversity on group functioning. Academy of Management Journal, 45, 1029-1045.

Hayes-Thomas, R. (2004). Why now? The contemporary focus on managing diversity. In M.S. Stockdale \& F.J. Crosby (Eds.), The psychology and management of workplace diversity (pp. 3-30). Malden, MA: Blackwell.

Hebl, M.R., Foster, J.B., Mannix, L.M., \& Dovidio, J.F. (2002). Formal and interpersonal discrimination: A field study of bias toward homosexual applicants. Personality and Social Psychology Bulletin, 28, 815-825.

Herek, G.M. (2000). The psychology of sexual prejudice. Current Directions in Psychological Science, 9, 19-22.

Holladay, C.L., Knight, J.L., Paige, D.L., \& Quinones, M.A. (2003). The influence of framing on attitudes toward diversity training. Human Resource Development Quarterly, 14, 245-263.

Human Rights Campaign. (2009). The state of the workplace for lesbian, gay, bisexual, and transgender Americans: 2007-2008. Washington, DC: Human Rights Campaign Foundation.

James, L.R., Demaree, R.G., \& Wolf, G. (1993). $\mathrm{r}_{\mathrm{wg}}$ : An assessment of within-group interrater agreement. Journal of Applied Psychology, 78, 306-309.

Kozlowski, S.W.J., \& Klein, K.J. (2000). A multilevel approach to theory and research in organizations: Contextual, temporal, and emergent processes. In K.J. Klein \& S.W.J. Kozlowski (Eds.), Multilevel theory, research, and methods in organizations: Foundations, extensions, and new directions (pp. 3-90). San Francisco: Jossey-Bass.

Krane, V., \& Barber, H. (2005). Identity tensions in lesbian intercollegiate coaches. Research Quarterly for Exercise and Sport, 76, 67-81. 
Plummer, D. (2006). Sportophobia: Why do some men avoid sport? Journal of Sport and Social Issues, 30, 122-137.

Prasad, P., Pringle, J.K., \& Konrad, A.M. (2006). Examining the contours of workplace diversity: Concepts, contexts, and challenges. In A.M. Konrad, P. Prasad, \& J.K. Pringle (Eds.), Handbook of workplace diversity (pp. 1-22). Thousand Oaks, CA: Sage.

Pugh, S.D., Dietz, J., Brief, A.P., \& Wiley, J.W. (2008). Looking inside and out: The impact of employee and community demographic composition on organizational diversity climate. Journal of Applied Psychology, 93, 1422-1428.

Ragins, B.R. (2004). Sexual orientation in the workplace: The unique work and career experiences of gay, lesbian and bisexual workers. Research in Personnel and Human Resources Management, 23, 35-120.

Ragins, B.R., \& Cornwell, J.M. (2001). Pink triangles: Antecedents and consequences of perceived workplace discrimination against gay and lesbian employees. Journal of Applied Psychology, 86, 1244-1261.

Ragins, B.R., Singh, R., \& Cornwell, J.M. (2007). Making the invisible visible: Fear and disclosure of sexual orientation at work. Journal of Applied Psychology, 4, 1103-1118.

Rogelberg, S.G., \& Stanton, J.M. (2007). Introduction: Understanding and dealing with organizational study nonresponse. Organizational Research Methods, 10, 195-209.

Rogelberg, S.G., \& Luong, A. (1998). Nonresponse to mail surveys: A review and guide. Current Directions in Psychological Science, 7(2), 60-65.

Sartore, M.L., \& Cunningham, G.B. (2009). Sexual prejudice, participatory decisions, and panoptic control: Implications for sexual minorities in sport. Sex Roles, 60, 100-113.

Schneider, B. (1987). The people make the place. Personnel Psychology, 40, 437-453.

Smith, N. G., \& Ingram, K. M. (2004). Workplace heterosexism and adjustment among lesbian, gay, and bisexual individuals: The role of unsupportive interactions. Journal of Counseling Psychology, 51, 57-67.

Snow, C.C., \& Hrebiniak, L. (1980). Strategy, distinctive competence, and organizational performance. Administrative Science Quarterly, 25, 317-335.

van Knippenberg, D., \& Schippers, M.C. (2007). Work group diversity. Annual Review of Psychology, 58, 515-541.

Zgonc, E. (2010). Race and gender demographics: 2009-2009 NCAA member institutions personnel report. Indianapolis, IN: National Collegiate Athletic Association. 